or natural selection; and it should be carefully studied by any metaphysician who still follows the ignis fatuus of induction-even though he will find the terminology difficult.

\section{Illustrated Obstetrics}

J. M. Holmes, M.D., M.B., B.S.(LOND.), M.R.C.o.G. Pp. xii +336 , illustrated. London: Butterworth. I962. 50s.

This is a disappointing book. A lot of work has clearly gone into it but the photographic reproduction is disappointing and the subject matter is uneven in its quality. There is an imbalance in the amount of space devoted to each subject. Cæsarean section, for example, occupies 36 pages and Ante-Partum Hæmorrhage three and a half pages, while the puerperium is not mentioned.

The author does not explain why he should include a discussion on acute appendicitis and intestinal obstruction only, among the many intercurrent diseases that may complicate pregnancy, nor is it obvious why there should be a chapter at the end of the book describing the operation of circumcision.

On page 94, the author says that castor oil is seldom successful in inducing labour whereas, on page 193, ' labour can usually be induced by such simple methods as the administration of castor oil '. On page 239, he says rickets no longer occurs in Britain! His account of the causes of abnormal labour is confused and some of his methods of delivery are debatable.

The book could profitably undergo revision and, with more experience, might prove useful.

\section{An Introduction to Psychiatry}

Max Valentine, M.D., D.P.M. Second edition. Pp. viii + 316. Edinburgh and London: E. \& S. Livingstone. 1962. 2 Is.

This book provides a short, clear introduction to psychiatry. The author is pleasingly broad and nonsectarian in his approach.

Passing reference is made to most ætiological theories and hypotheses and a short account is provided of the historical development of psychiatric thought and practice. There are chapters on methods of interviewing patients, examination of the mental state, psychological testing and special methods of treatment. Appropriate space is given to discussing psychiatric syndromes in children and adults. One of the author's aims in this new edition has been to expound on the 1959 Mental Health Act which he does clearly and enthusiastically. Another aim has been to devote space to discussing the welter of new sedative, tranquillizing and anti-depressive drugs which have been marketed in recent years. He has succeeded admirably in this; unfortunately-although this field seems promising in many ways-present reports, particularly about the value of the currently available anti-depressive drugs, are still conflicting and inadequate. Already two of the drugs which he discusses, thalidomide (Distaval) a hypnotic: and pheniprazine (Cavodil), an anti-depressant drug of the hydrazine group, have been withdrawn from the market because of their newly discovered toxic effects.

There is a useful appendix of case interviews which suffers only from the inevitable disability of the author being unable to fully convey the various appropriate affective contexts within each interview. Each chapter is concluded by a series of specific references and a list of books suitable for further reading; it is a pity that outdated editions are often quoted in the latter list.
To conclude, this is a lucid introduction to psychiatry; it makes easy reading and will be particularly useful to students, general practitioners, and busy medical and surgical registrars wishing to orientate themselves within the subject.

\section{Drugs in Anæsthetic Practice}

F. G. Wood-Smith and H. C. Stewart. Pp. vii + 464. London: Butterworth. 1962. $63 s$.

Most anæsthetists know too little pharmacology; most pharmacologists, too little anæsthesia. One might have hoped that 'Drugs in Anæsthetic Practice' would go some way towards remedying this state of affairs but, alas, it merely adds confirmation.

The general standard of accuracy and detail falls far below anything that will be required by the "students studying for higher examinations in anæsthesia and practising anæsthetists who require a book of reference' mentioned in the preface. The authors have also saved themselves much trouble, at the reader's expense, by taking the view that 'much of the information given is well-known and references are not needed'. Dr. C. L. Cope has contributed a section on corticosteroids, and Dr. P. J. Horsey has written a section on electrolytes and infusion fluids which is by far the best part of the book.

The writing begins with all the elegance of a schoolboy's first essay; subsequently, some improvement is occasionally discernible, but throughout the book the English remains bad. At a lower price, anæsthetists would find some of the ' non-anæsthetic' sections useful as a quick means of bringing themselves up-to-date. The 'anæsthetic' sections are an insult to the intelligence.

\section{The Spread of Carcinoma of the Bronchus}

H. C. NohL, D.M., F.R.C.s. Pp. viii +80 , illustrated. London: Lloyd-Luke. I 5 s.

The title of this work is somewhat misleading since it is almost entirely concerned with spread of lung cancer by lymphatics and by the blood stream and direct spread gets only scanty attention. It is, in fact, an expansion of Dr. Nohl's previously published articles on the lymphatic and hæmatogenous pathways of spread of carcinoma of the bronchus. The work has been put into historical perspective and the detailed anatomy of the lymphatic drainage of the lung is described. His contribution is particularly valuable in respect of his modifications of Rouviere's somewhat inaccurate, but much quoted, descriptions of intra-pulmonary lymphatics.

The work on these methods of spread has been related to the surgical treatment of carcinoma of the bronchus and as a support for the concept of lobectomy as a definitive operation for this disease. It is further utilized to lend support to a surgico-pathological staging of lung cancer as a guide to prognosis. Evidence is presented justifying the use of the author's modification of Salzer's classification which should recommend its wide acceptance.

The subject matter is clearly and concisely written, the diagrams and other illustrations are well selected and clear and the presentation is of high standard.

The book will naturally have a limited appeal and I suspect is only intended for those primarily interested in thoracic surgery and pathology. To all persons, however, interested in the problems of bronchogenic carcinoma, this short work will be most valuable. 